\title{
Tracing Performance Evaluation on Ergonomics Mouse Base on Steering Law
}

\author{
Waraporn Phithugthummakun and Phairoat Ladavichitkul
}

\begin{abstract}
There are many pointing device for computer usage especially device so call "Mouse". Mouse is a wildly use standard device which can effect user if using for a long time such as carpal tunnel syndrome (CTS). Ergonomics mouse or mouse that angle has been designed to suit with human low risk to have CTS. But ergonomics mouse is not widespread because of price and skill of each person, Steering law has been used to evaluate the performance of regular mouse with ergonomics mouse. The Index of difficulty (ID) is set between 16-42 total of 6 condition, The result show ergonomics mouse angle 90 degree performance is better than regular mouse at height ID.
\end{abstract}

Index Terms-Steering law, ergonomics mouse, performance evaluation, index of difficulty.

\section{INTRODUCTION}

Presently, Computer has a lot of variety of using such a office work, storage document, or design. Pointing device is one kind of supporting computer function. Base on IS09241-9-2000 pointing device can divide in 2 types: 1) Direct pointing such as finger or stylus 2) Indirect pointing such as mouse trackball touchpad [1] by the variety pointing device steering law was used for evaluation performance of pointing device 5 pointing device mouse, tablet, trackball, touchpad and track point the result show performance of mouse is $2^{\text {nd }}$ highly from tablet [2]. Using mouse for a long time can effect to user and has potential factor in case Carpal Tunnel Syndrome (CTS). Ergonomics mouse was design for fit the human body safe for using and reduce risk of CTS.

Therefor ergonomics mouse is not extensively use due to high price and familiarity with regular mouse. Find the effect of physical angle with performance of mouse by Fitts' law is can support the decision of mouse user to find movement time when move the cursor from start point to end point by identify distance and width of target the result show 4 of 5 subject is use ergonomics mouse better performance than regular mouse [3].

Pointing device not only for pointing task but also variety of use such as drawing tracing, tracing is following the outline of an image by moving the cursor or input device over the line or shape of an image. Fitts' law can find only performance of point task not cover to drawing and tracing so we have to find performance by steering law, Steering law describing the motion of an object from one point to another

Manuscript received April 1, 2014; revised June 28, 2014.

Waraporn Phithugthummakun and Phairoat Ladavichitkul are with the Industrial Engineering Department, Faculty of Engineering, Chulalongkorn University, Bangkok, Thailand (e-mail: beebee_naruk@hotmail.com, phairoat@hotmail.com). point by tracing past certain limits. As shown in Fig. 1, The relationship equation [4] $M T=a+b \times I D$.

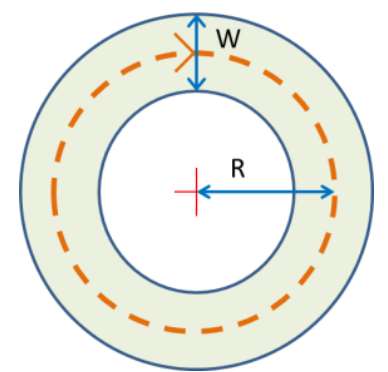

Fig. 1. Pointing task for circular tracing $\mathrm{W}=$ Target width, $2 \pi \mathrm{R}=$ Target distance.

Because ergonomics mouse has designed taking into account the human factor apply angle of mouse in design to reduce risk of CTS. Steering law was used to consideration of change angle of mouse's design is necessary factor of performance design.

\section{METHODOLOGY}

\section{A. Subjects}

9 Volunteers participant age vary from 24-35 years old, with both male and female. All Participants have experience using regular mouse more than 1 year with right hand and never use ergonomics mouse in experience. Healthy and no pain on hand.

\section{B. Equipment}

1) 3 types of mouse 1. Regular mouse 2. Ergonomics mouse angle 45 degree 3 . Ergonomics mouse angle 90 degree. As show in Fig. 2 Pattharaporn evaluate an effect on mouse weight. After comparing mouse weight found that weight has effect work performance [5]. Consequently researcher has to balance same weight with tester mouse.
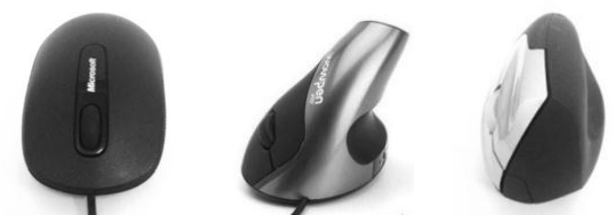

Fig. 2. (Right) Regular mouse; (Center) Ergonomics mouse angle 45 degree; (Left) Ergonomics mouse angle 90 degree.

2) LCD Screen size 17 inch with $1280 \times 1024$ pixel full display.

3) Evaluation program for check movement time base on steering law. Program can adjust i) distance target by vary Radius of circular: $R$, ii) width of target: $W$ Evaluation by use clockwise direction and counter clockwise direction see as Fig. 3 program record movement time of tracing mouse. 


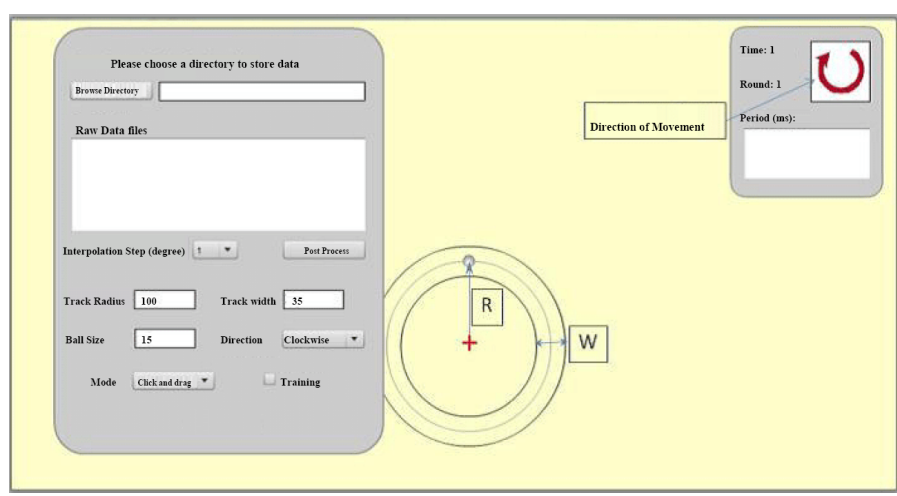

Fig. 3. Program that use for evaluate.

4) Testing condition with 6 difference Index of Difficulty(ID) in 6 level by vary with of target 25,30,35,45,65 and 80 pixel with 3 level of distance target by vary radius : 100,200 and 300 pixel show in Table I.

5) For control effect from environment work station was designed by ergonomics method use ergonomic lab to work by control condition with $25{ }^{\circ} \mathrm{C}$ temperature, 600 lux Illuminance, 80 centimeter table height and adjustable backboard chair.

TABLE I: INDEX OF DIFFICULTY

\begin{tabular}{c|c|c|c}
\hline \hline Condition & $\begin{array}{c}\text { Index of } \\
\text { Difficulty : ID }\end{array}$ & $\begin{array}{c}\text { Radius } \\
: \text { R (Pixel) }\end{array}$ & $\begin{array}{c}\text { Target Width } \\
: \text { W (Pixel) }\end{array}$ \\
\hline 1 & 16 & 200 & 80 \\
2 & 21 & 100 & 30 \\
3 & 25 & 100 & 25 \\
4 & 29 & 300 & 65 \\
5 & 36 & 200 & 35 \\
6 & 42 & 300 & 45 \\
\hline Maximum & 42 & 300 & 80 \\
Minimum & 16 & 100 & 25 \\
\hline \hline
\end{tabular}

\section{Experimental Design}

Participants have trained for using program one by one using characteristic 3 types of mouse for 10 minute and 1 minute to rest before testing start. Testing condition participants have to use mouse with 6 index of difficulty, The order of the three devices test 10 trails for each index of difficulty and 2 directions of testing clockwise direction and counterclockwise direction totally 360 times for each participant.

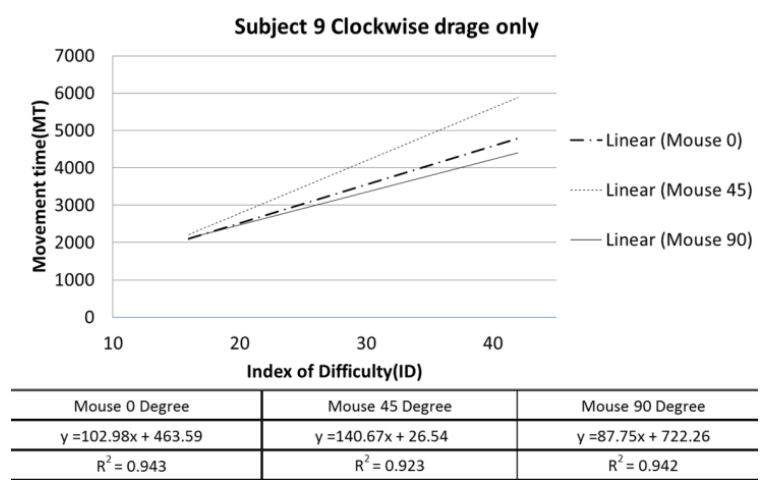

Fig. 4. Example performance compare between regular mouse angel 0 degree (Mouse 0) Ergonomics mouse angle 45 degree(Mouse 45) and Ergonomics mouse angle 90 degree(Mouse 90).

\section{EXPERIMENTAL RESULT AND DATA ANALYSIS}

According to tracing of mouse show a relative between movement time in millisecond unit with Index of Difficulty of 3 type of mouse from 9 participants. A result shown, more difficult task, It take more time regression line equations show $M T=b X+a$.

From Fig. 4 show example relation linear regression between Index of Difficulty (ID) and Movement Time (MT) performance of regular mouse angle 0 degree, ergonomics mouse 45 degree and ergonomics mouse 90 degree is inverse of slope $(1 / b)$.

\section{A. Clockwise Direction}

Comparing performance between regular mouse and ergonomics mouse angle 45 degree shows 5 in 9 participants performance of regular mouse better than ergonomics mouse angle 45 degree all result show in Table II.

Comparing performance between regular mouse and ergonomics mouse angle 90 degree shows 6 in 9 participants performance of ergonomics mouse angle 90 degree better than regular mouse all result show in Table II.

Compared to standard deviation (SD) between regular mouse and ergonomics mouse angle 45 degree at lowest index of difficulty (ID) 6 in 9 participants show result of regular mouse lower variation than ergonomics mouse angle 45 degree see as Fig. 5. At highest index of difficulty (ID) 6 in 9 participants show result of regular mouse still lower variation than ergonomics mouse angle 45 degree see as Fig. 6.

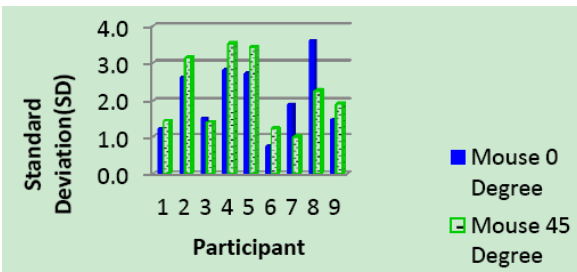

Fig. 5. comparing standard deviation at low index of difficulty between regular mouse and ergonomics mouse 45degree for clockwise direction.
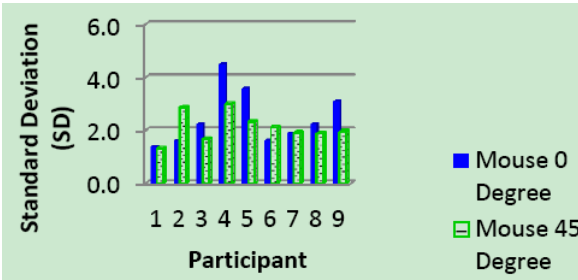

Fig. 6. comparing standard deviation at high index of difficulty between regular mouse and ergonomics mouse 45 degree for clockwise direction.

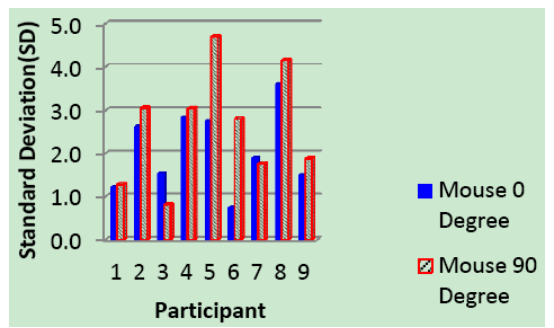

Fig. 7. comparing standard deviation at low index of difficulty between regular mouse and ergonomics mouse 90 degree for clockwise direction.

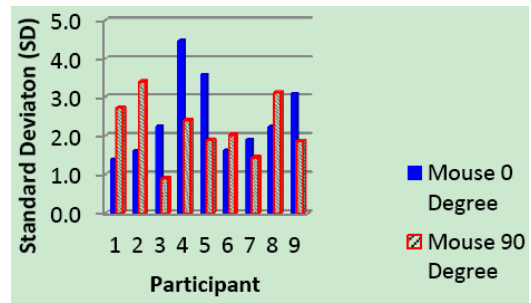

Fig. 8. comparing standard deviation at high index of difficulty between regular mouse and ergonomics mouse 90 degree for clockwise direction. 
TABLE II: Result of Linear Regression Equation, R-SQuare $\left(R^{2}\right)$ AND INdeX of Performance (IP) FOR Regular Mouse, ERgONOMics Mouse ANGLE 45 Degree, ERGONOMics MOUSE ANGLE 90 DEGREe AT ClOCKWISE DiRECTION

\begin{tabular}{c|l|l|l|l|l|l|l|l|l}
\hline \hline \multirow{2}{*}{ condition } & \multicolumn{3}{|c|}{$\begin{array}{c}\text { Regular Mouse angle } \\
\text { 0 Degree }\end{array}$} & \multicolumn{2}{c|}{$\begin{array}{c}\text { Ergonomics Mouse angle } \\
\text { 45 Degree }\end{array}$} & \multicolumn{3}{c}{$\begin{array}{c}\text { Ergonomics Mouse angle } \\
90 \text { Degree }\end{array}$} \\
\cline { 2 - 10 } & \multicolumn{1}{|c|}{$\begin{array}{c}\text { Linear Regression } \\
\text { Equation }\end{array}$} & $R^{2}$ & $I P$ & $\begin{array}{c}\text { Linear Regression } \\
\text { Equation }\end{array}$ & $R^{2}$ & $I P$ & $\begin{array}{c}\text { Linear Regression } \\
\text { Equation }\end{array}$ & $R^{2}$ & $I P$ \\
\hline 1 & $Y=66.51 x+1099.00$ & 0.987 & 0.015 & $Y=54.60 x+1021.40$ & 0.921 & 0.018 & $Y=63.70 x+852.81$ & 0.827 & 0.016 \\
2 & $Y=104.27 x+769.17$ & 0.952 & 0.010 & $Y=150.58 x+348.24$ & 0.971 & 0.007 & $Y=120.03 x+966.26$ & 0.980 & 0.008 \\
3 & $Y=72.23 x+647.17$ & 0.977 & 0.014 & $Y=73.61 x+746.04$ & 0.993 & 0.014 & $Y=92.16 x+680.08$ & 0.943 & 0.011 \\
4 & $Y=156.45 x+662.69$ & 0.894 & 0.006 & $Y=149.59 x+528.75$ & 0.963 & 0.007 & $Y=131.85 x+914.93$ & 0.942 & 0.008 \\
5 & $Y=118.17 x+588.70$ & 0.834 & 0.008 & $Y=164.94 x+1175.8$ & 0.973 & 0.006 & $Y=99.48 x+1648.70$ & 0.785 & 0.010 \\
6 & $Y=88.48 x+883.15$ & 0.872 & 0.011 & $Y=74.02 x+1415.20$ & 0.932 & 0.014 & $Y=78.71 x+765.12$ & 0.802 & 0.013 \\
7 & $Y=52.63 x+1123.30$ & 0.977 & 0.019 & $Y=66.83 x+927.78$ & 0.899 & 0.015 & $Y=47.76 x+1335.60$ & 0.729 & 0.021 \\
8 & $Y=132.25 x+719.53$ & 0.939 & 0.008 & $Y=118.05 x+1413.3$ & 0.892 & 0.008 & $Y=204.65 x-360.80$ & 0.860 & 0.005 \\
9 & $Y=102.98 x+463.59$ & 0.943 & 0.010 & $Y=140.67 x-26.54$ & 0.923 & 0.007 & $Y=87.75 x+722.26$ & 0.942 & 0.011 \\
\hline \hline
\end{tabular}

TABLE III: RESUlt OF LiNEAR REgRESSION EQUATION, R-SQUARE $\left(R^{2}\right)$ AND INDEX OF PERFORMANCE (IP) FOR REGULAR MOUSE, ERGONOMICS MOUSE ANGle 45 Degree, ERgonomics Mouse ANGle 90 Degree at Counter ClockWISE DiReCTION

\begin{tabular}{|c|c|c|c|c|c|c|c|c|c|}
\hline \multirow{2}{*}{ condition } & \multicolumn{3}{|c|}{$\begin{array}{c}\text { Regular Mouse angle } \\
\text { 0 Degree }\end{array}$} & \multicolumn{3}{|c|}{$\begin{array}{c}\text { Ergonomics Mouse angle } \\
\text { 45 Degree }\end{array}$} & \multicolumn{3}{|c|}{$\begin{array}{c}\text { Ergonomics Mouse angle } \\
90 \text { Degree }\end{array}$} \\
\hline & $\begin{array}{l}\text { Linear Regression } \\
\text { Equation }\end{array}$ & $R^{2}$ & IP & $\begin{array}{l}\text { Linear Regression } \\
\text { Equation }\end{array}$ & $R^{2}$ & IP & $\begin{array}{l}\text { Linear Regression } \\
\text { Equation }\end{array}$ & $R^{2}$ & IP \\
\hline 1 & $Y=76.818 x+817.07$ & 0.9584 & 0.013 & $y=58.657 x+1165.2$ & 0.8207 & 0.017 & $y=69.978 x+859.48$ & 0.784 & 0.014 \\
\hline 2 & $Y=131.47 x+505.59$ & 0.9164 & 0.008 & $y=100.31 x+1829.1$ & 0.9537 & 0.010 & $y=121.29 x+1026.7$ & 0.9734 & 0.008 \\
\hline 3 & $Y=72.944 x+781.26$ & 0.9398 & 0.014 & $y=100.56 x+672.23$ & 0.8691 & 0.010 & $y=96.343 x+98.547$ & 0.8074 & 0.010 \\
\hline 4 & $Y=142.53 x+597.78$ & 0.9484 & 0.007 & $y=136.2 x+499.03$ & 0.9383 & 0.007 & $y=113.92 x+1213$ & 0.9237 & 0.009 \\
\hline 5 & $Y=80.064 x+1598.9$ & 0.9616 & 0.012 & $y=98.385 x+1214.7$ & 0.7372 & 0.010 & $y=108.29 x+368.03$ & 0.9834 & 0.009 \\
\hline 6 & $Y=72.362 x+1006.9$ & 0.717 & 0.014 & $y=75.191 x+879.94$ & 0.8565 & 0.013 & $y=86.668 x+693.15$ & 0.9333 & 0.012 \\
\hline 7 & $Y=63.126 x+902.61$ & 0.9691 & 0.016 & $y=70.979 x+743.04$ & 0.8649 & 0.014 & $y=79.291 x+660.54$ & 0.9178 & 0.013 \\
\hline 8 & $Y=161.86 x+88.225$ & 0.9782 & 0.006 & $y=137.49 x+556.8$ & 0.9493 & 0.007 & $y=126.64 x+474.98$ & 0.9817 & 0.008 \\
\hline 9 & $Y=72.875 x+1264.5$ & 0.9633 & 0.014 & $y=113.21 x+860.85$ & 0.8881 & 0.009 & $y=94.847 x+711.74$ & 0.8411 & 0.011 \\
\hline
\end{tabular}

\section{B. Counterclockwise Direction}

Comparing performance between regular mouse and ergonomics mouse angle 45 degree shows 5 in 9 participants performance of regular mouse better than ergonomics mouse angle 45 degree. All the results are shown in Table III.

Comparing performance between regular mouse and ergonomics mouse angle 90 degree shows 5 in 9 participants performance of ergonomics mouse angle 90 degree better than regular mouse. All the results are shown in Table III.

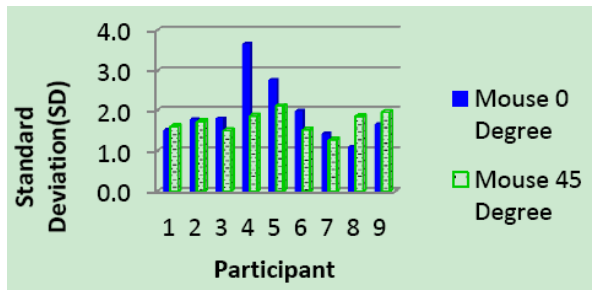

Fig. 9. Comparing standard deviation at low index of difficulty between regular mouse and ergonomics mouse 45 degree for counterclockwise direction.

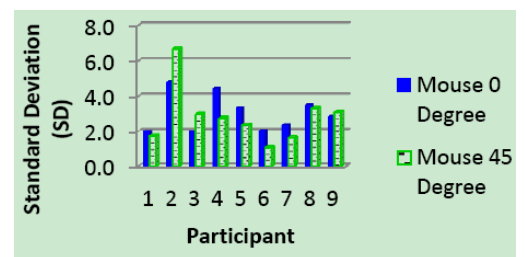

Fig. 10. Comparing standard deviation at high index of difficulty between regular mouse and ergonomics mouse 45 degree for counterclockwise direction.
Compared to standard deviation (SD) between regular mouse and ergonomics mouse angle 45 degree at lowest index of difficulty (ID) 6 in 9 participants show result of ergonomics mouse angle 45 degree lower variation than regular mouse see as Fig. 9. At highest index of difficulty (ID) 6 in 9 participants show result of ergonomics mouse angle 45 degree still lower variation than regular mouse see as Fig. 10.

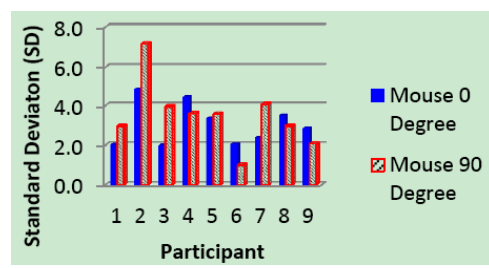

Fig. 11. Comparing standard deviation at low index of difficulty between regular mouse and ergonomics mouse 90 degree for counterclockwise direction.

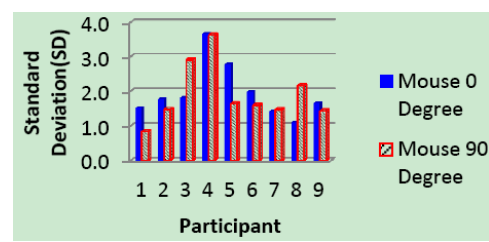

Fig. 12. Comparing standard deviation at high index of difficulty between regular mouse and ergonomics mouse 90 degree for counterclockwise direction.

Compare to standard deviation (SD) between regular mouse and ergonomics mouse angle 90 degree at lowest 
index of difficulty (ID) 5 in 9 participants show result of regular mouse lower variation than ergonomics mouse angle 90 degree see as Fig. 11. At highest index of difficulty (ID) 6 in 9 participants show result of ergonomics mouse angle 90 degree lower variation than regular mouse see as Fig. 12.

\section{DisCUSSION AND CONCLUSION}

This research has compared performance of regular mouse with ergonomics mouse angle 45 degrees and 90 degrees by tracing follow Steering Law, considering the performance, found ergonomics mouse angle 90 degree performance better than a regular mouse, but ergonomics mouse angle 45 degree performance lower than regular mouse.

Most people use regular mouse well at low index of difficulty because of familiarity and the movement just only the wrist point and holding mouse have friction between hand and table that responded to performance of mouse as show in Fig. 13.
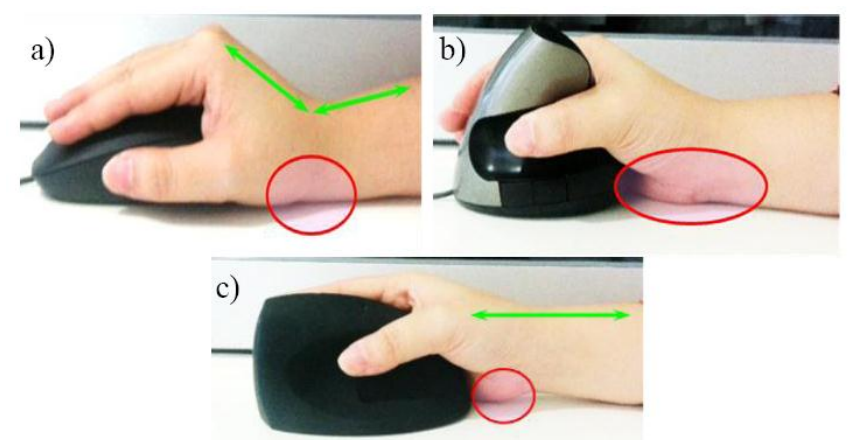

Fig. 13. Friction of mouse holding a) Regular mouse, b) Ergonomics mouse angle 45 degree, c) Ergonomics mouse angle 90 degree respectively.

When the index of difficulty increase ergonomics mouse angle 90 degree will work very well because at more index of difficulty not only wrist movement but also wrist and elbow movement parallel and ergonomics mouse was designed for support human factor to make performance of ergonomics mouse.

\section{REFERENCES}

[1] ISO9241-9, ISO Standard 2000-02-15.

[2] J. Acot and S. Zhai, "Performance evaluation of input devices in trajectory-based tasks: An application of the steering law," in Proc. SIGCHI Conference on Human Factors in Computing system, May 15-20, 1999

[3] P. Kiartidhama, "Relationship between mouse physical characteristics and user performance," M.E thesis, Department of Industrial Engeering, Chulalonkorn University, Bangkok, Thailand, 2012.

[4] S. Zhai and R. Woltjer, "Human movement performance in relation to path constraint - the law of steering in locomotion," in Proc. IEEE Virtual Reality 2003, March 2003, pp.149-156.

[5] P. Kiartidhama and P. Luengchameekorn, "The effect of mouse weight on speed and accuracy of pointing," presented at IE Network Conference.

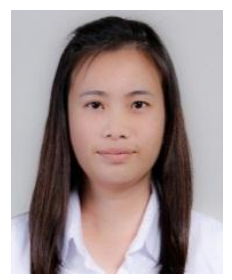

Waraporn Phithugthummakun was born in Songkhla, Thailand in 1986. She received the bachelor of engineering degree in industrial engineering from Prince of Songkla University the campus in Hatyai, Thailand in 2007 and Master degree in Industrial Engineering from Chulalongkorn University, Thailand in 2014, respectively.

She is currently a design engineer at Honda R\&D

Asia Pacific, Thailand

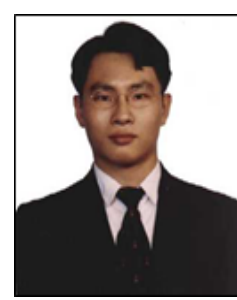

Phairoat Ladavichitkul received the bachelor of engineering degree in industrial engineering from Chulalongkorn University in 1997 and master of engineering degree in industrial engineering from Chulalongkorn University Thailand in 1999, and $\mathrm{Ph} . \mathrm{D}$. of Engineering in Texas Tech University in 2008, respectively

$\mathrm{He}$ is currently a lecturer at the Department of Industrial Engineering, Chulalongkorn University, Thailand. His expertise are focused on ergonomics, human factors in engineering, safety engineering. 